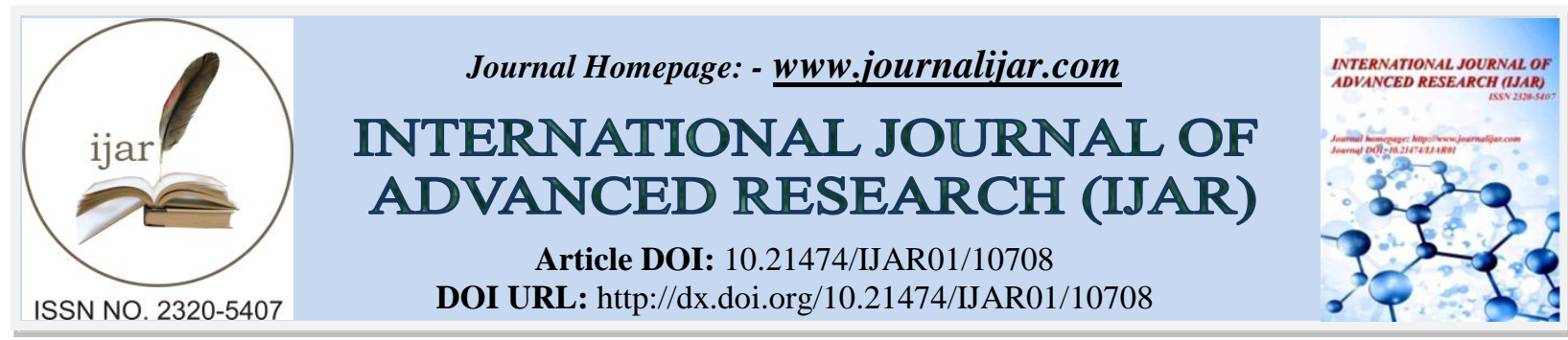

RESEARCH ARTICLE

\title{
PERSONALITY ADJUSTMENT OF POST GRADUATE TEACHERS IN DEHRADUN
}

\author{
Bharat Kumar \\ PGT Chemistry, Doon International School, Dehradun, Uttarakhand, India, 248001, P.G.D.C.F.T. Scholar, IGNOU, \\ New Delhi, India.
}

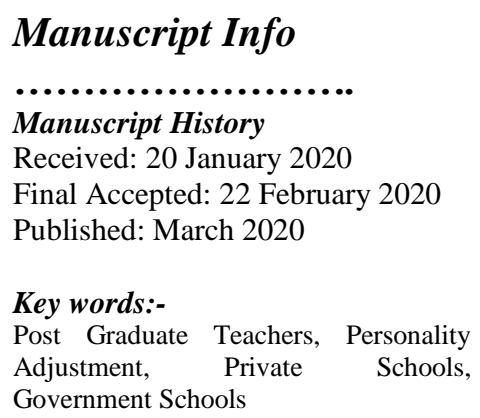

Manuscript Info

Manuscript History

Final Accepted: 22 February 2020

Key words:-

Adjustment, Private Schools,

Government Schools

\begin{abstract}
The objective of this study was to study the level of personality adjustment among post graduate teachers working in Dehradun. The researcher used descriptive method involving measurement, evaluation, comparison, and interpretation. Total 360 PGTs from private and government schools were assessed. Personality adjustment inventory developed by C.P. Sharma was used to measure different levels of personality adjustment. Frequency and percentage were used for descriptive analysis and $\chi^{2}$ test was applied for statistical analysis of data and to find out significant difference among PGTs. $48.89 \%$ female PGTs were having good personality adjustment as compared with $38.88 \%$ males. While $28.33 \%$ male PGTs had shown poor personality adjustment as compared with $12.22 \%$ females. Among private school PGTs, $53.33 \%$ females were having good personality adjustment as compared with $42.22 \%$ males and $24.44 \%$ males had poor personality adjustment as compared with $5.56 \%$ females. Among PGTs working in government school, $45.56 \%$ female were having good personality adjustment as compared with $34.44 \%$ males. While $34.44 \%$ males were having poor personality adjustment as compared with $16.67 \%$ females. Among male PGTs, 42.22\% private schools PGTs were having good personality adjustment as compared with $34.44 \%$ of government school male PGTs while $34.44 \%$ males from government school were at poor personality adjustment level as compared with $24.44 \%$ males of private schools. $53.33 \%$ private school females PGTs were having good personality adjustment while only $45.56 \%$ from government schools.
\end{abstract}

Copy Right, IJAR, 2020,. All rights reserved.

\section{Introduction:-}

A well adjusted teacher will be able to achieve successes that are needed by the nature of his job to his strenuous life to work and study. Adjustment refers to such abilities as of making decisions of assuming responsibilities in accordance with one's capacities of finding satisfaction success and happiness. Both personal and environmental factors, work side by side in adjustment, the senior school teachers achieved well when the environment yields constructive activities.

As the children are influenced by the personality of teachers, so they should have high emotional maturity and moral character. They should possess loving and affectionate attitude towards children and should enjoy teaching profession. 


\section{Objective of the Study:-}

1. To find out difference in the personality adjustment of private and government school post graduate teachers (PGTs).

2. To compare the personality adjustment of male and female PGTs.

3. To compare the personality adjustment of male and female PGTs working in private schools.

4. To compare the personality adjustment of male and female PGTs working in government schools.

5. To compare the personality adjustment of male PGTs working in private and government schools.

6. To compare the personality adjustment of female PGTs working in private and government schools.

\section{Hypotheses of the Study:}

1. There is no significant difference in the degree of personality adjustment of PGTs working in private and government schools.

2. There is no significant difference in the degree of personality adjustment of male and female PGTs.

3. There is no significant difference in the degree of personality adjustment of male and female PGTs working in private schools.

4. There is no significant difference in the degree of personality adjustment of male and female PGTs working in government schools.

5. There is no significant difference in the degree of personality adjustment of male PGTs working in private and government schools.

6. There is no significant difference in the degree of personality adjustment of female PGTs working in private and government schools.

\section{Research Methodology:- \\ Population:}

For the present study, the population was the PGTs (Post graduate teachers) working in private and government schools located in Dehradun city.

\section{Lay Out of Sample:}

Researcher had randomly selected 360 PGTs from Dehradun, Uttarakhand. Out of 360 PGTs, 180 were selected from 10 government schools and 180 from 10 private schools. From each school 09 males and 09 females PGTs were selected.

\section{Procedure of Data Collection:}

The collection of data was spread over a period of 90 days (July to September 2019).The researcher personally visited the selected schools. The researcher sought the permission from head of the school for administering the scales. On the schedule date the researcher met the teachers and cleared the purpose of research. The instructions were explained and doubts were clarified. They were assured that their response will be used for research purpose only and will be kept confidential. They were suggested to give free frank and honest responses without any hesitation. The scales were collected only after responded by the subjects. After the completion of the inventories, the investigator conveyed his gratitude and thanks to the teacher and head of the school for their kind help and cooperation.

\section{Tools Used For Data Collection:}

To measure the personality adjustment of PGTs, personality adjustment inventory, developed by C.P. Sharma (1977), was used. Scores were divided into three categories as in Table: 1.

Table 1:- Interpretation of Raw Scores of Personality Adjustment Inventory.

\begin{tabular}{|l|l|}
\hline Range of Scores & Interpretation \\
\hline Above 18 & Good personality adjustment \\
\hline Between $16-18$ & Average personality adjustment \\
\hline Below 16 & Poor personality adjustment \\
\hline
\end{tabular}

\section{Statistical Techniques Used:}

In order to know the degree of personality adjustment, the researcher used percentage for descriptive analysis and $\chi^{2}$ test was used for inferential analysis also to find out the significant difference. 
Administration, Scoring and Interpretation of Personality Adjustment Inventory:

After the subjects were seated then the inventories were distributed to them. The subjects were asked to fill up the columns of name age, sex, class etc. printed on the cover page. To ensure careful reading of the instructions appearing on the cover page, the researcher read them loudly and subject read them silently. After the subjects read out instructions, their doubts were cleared. The subjects were then asked to turn the page and to begin answering the items. No time limit was imposed, ordinarily not more than fifteen to twenty minutes were required for all subjects to complete the inventory. In this inventory the two category response type 'Yes' and 'No' was used 'Yes' responses were considered to the correct answers, i.e. the individual shows the neurotic tendency and the 'no' responses show otherwise, one mark was given to the 'yes' answer and zero to the 'No' answer. The sum of scores shows the degree of neurotic tendency of the individual.

Statistical analysis of scores obtained for personality adjustment of PGTs:

Table 2:- Scores for Personality Adjustment of PGTs.

\begin{tabular}{|l|l|l|l|l|l|l|}
\hline & Total PGTs & \multirow{2}{*}{ Adjustment Category } & & PGTs & \multicolumn{2}{l|}{} \\
\cline { 4 - 7 } & & $\%$ & Pvt. School & $\%$ & Govt. School & $\%$ \\
\hline Good Personality & $\mathbf{1 5 8}$ & $\mathbf{4 3 . 8 9}$ & $\mathbf{8 6}$ & $\mathbf{4 7 . 7 8}$ & $\mathbf{7 2}$ & $\mathbf{4 0}$ \\
\hline Average Personality & $\mathbf{1 2 9}$ & $\mathbf{3 5 . 8 3}$ & $\mathbf{6 7}$ & $\mathbf{3 7 . 2 2}$ & $\mathbf{6 2}$ & $\mathbf{3 4 . 4 4}$ \\
\hline Poor Personality & $\mathbf{7 3}$ & $\mathbf{2 0 . 2 8}$ & $\mathbf{2 7}$ & $\mathbf{1 5}$ & $\mathbf{4 6}$ & $\mathbf{2 5 . 5 6}$ \\
\hline Total & $\mathbf{3 6 0}$ & $\mathbf{1 0 0}$ & $\mathbf{1 8 0}$ & $\mathbf{1 0 0}$ & $\mathbf{1 8 0}$ & $\mathbf{1 0 0}$ \\
\hline
\end{tabular}

Researcher calculated $\chi^{2}$ value to find out significant difference between private and government school PGTs with regard to their personality adjustment. (Table 3 )

Table 3:- Comparison of Personality Adjustment of Private and Government School PGTs.

\begin{tabular}{|l|l|l|l|l|l|}
\hline \multirow{2}{*}{ School Type } & \multicolumn{3}{|l|}{ PGTs as per personality adjustment } & \multirow{2}{*}{$\chi^{2}$ Value } & \multirow{2}{*}{ Result } \\
\cline { 2 - 4 } & Good & Average & Poor & & \\
\hline Private & 86 & 67 & 27 & & Significant at 95\% \\
\hline Government & 72 & 62 & 46 & 6.3795 & \\
\hline
\end{tabular}

Table 3 reveals that the calculated value for $\chi^{2}$ is 6.3795 , which is less than the table value at $95 \%$ level of significance. Hence the $1^{\text {st }}$ null hypothesis is rejected. So it can be concluded that there is a significant difference in the degree of personality adjustment between PGTs working in private and government schools in Dehradun.

Interpretation of Scores for Male and Female PGTs:

Table: 4 reveal that out of 360 PGTs, 158 PGTs have good personality adjustment, 129 have average personality adjustment and 73 PGTs have poor personality adjustment. Therefore, $43.89 \%$ teachers have good personality adjustment, $35.83 \%$ teachers have average personality adjustment and 20.28\% school teachers have poor personality adjustment. Among male and female PGTs, more females have good personality adjustment (48.88\%) as compared to males (38.88\%). While male PGTs score more in poor category $(28.33 \%)$ as compared with female PGTs (12.22\%). In the average category of personality management, male and female PGTs have very less difference.

Table 4:- Scores for Personality Adjustment of PGTs.

\begin{tabular}{|l|l|l|l|l|l|l|}
\hline & Total PGTs & \multirow{2}{*}{ PGTs } & \multicolumn{4}{l|}{} \\
\cline { 4 - 8 } Adjustment Category & & Male & Female & $\%$ \\
\hline Good Personality & $\mathbf{1 5 8}$ & $\mathbf{4 3 . 8 9}$ & $\mathbf{7 0}$ & $\mathbf{3 8 . 8 8}$ & $\mathbf{8 8}$ & $\mathbf{4 8 . 8 8}$ \\
\hline Average Personality & $\mathbf{1 2 9}$ & $\mathbf{3 5 . 8 3}$ & $\mathbf{5 9}$ & $\mathbf{3 2 . 7 8}$ & $\mathbf{7 0}$ & $\mathbf{3 8 . 8 9}$ \\
\hline Poor Personality & $\mathbf{7 3}$ & $\mathbf{2 0 . 2 8}$ & $\mathbf{5 1}$ & $\mathbf{2 8 . 3 3}$ & $\mathbf{2 2}$ & $\mathbf{1 2 . 2 2}$ \\
\hline Total & $\mathbf{3 6 0}$ & $\mathbf{1 0 0}$ & $\mathbf{1 8 0}$ & $\mathbf{1 0 0}$ & $\mathbf{1 8 0}$ & $\mathbf{1 0 0}$ \\
\hline
\end{tabular}

Analysis of Scores Of Male And Female PGTS:

Calculated $\chi^{2}$ value is 14.5092 which is greater than p-value 0.000707 at $95 \%$ level of significance. So $\chi^{2}$ value is significant. Hence $2^{\text {th }}$ null hypothesis is rejected. So it can be concluded that there is a significant difference in the degree of personality adjustment of male and female PGTs (Table 5). 
Table 5:- Comparison of Personality Adjustment of PGTs.

\begin{tabular}{|l|l|l|l|l|l|l|}
\hline \multirow{2}{*}{ PGTs } & \multicolumn{3}{|l|}{ Personality Adjustment } & \multirow{2}{*}{$\chi^{2}$-value } & \multirow{2}{*}{ Result } & \\
\cline { 2 - 4 } & Good & Average & Poor & & Significant at & $\mathbf{9 5 \%}$ \\
\hline Male & $\mathbf{7 0}$ & $\mathbf{5 9}$ & $\mathbf{5 1}$ & $\mathbf{1 4 . 5 0 9 2}$ & level & \\
\hline Female & $\mathbf{8 8}$ & $\mathbf{7 0}$ & $\mathbf{2 2}$ &
\end{tabular}

Analysis of Scores Obtained for PGTs working in Private Schools:

Out of 90 male PGTs working in private schools, 38 teachers have good personality adjustment. 30 male teachers have average personality adjustment and 22 male teachers have poor personality adjustment. Among male and female PGTs of private school, females score more in good personality category (53.33\%) as compared with males $(42.22 \%)$. Males scored less in average category $(33.33 \%)$ as compared with females $(41.11 \%)$. In poor personality category again males scored more $(24.44 \%)$ as compared to females $(5.56 \%)$. In his way it can be concluded female can adjust personality better than male PGTs working in private schools in Dehradun (Table 6).

Table 6:- Statistical Analysis of Personality Adjustment of PGTs Working in Private Schools.

\begin{tabular}{|l|l|l|l|l|l|l|}
\hline $\begin{array}{l}\text { Category of Personality } \\
\text { Adjustment }\end{array}$ & $\begin{array}{l}\text { Total } \\
\text { PGTs }\end{array}$ & $\%$ & Male PGTs & $\%$ & Female PGTs & $\%$ \\
\hline Good Personality & $\mathbf{8 6}$ & $\mathbf{4 7 . 7 8}$ & $\mathbf{3 8}$ & $\mathbf{4 2 . 2 2}$ & $\mathbf{4 8}$ & $\mathbf{5 3 . 3 3}$ \\
\hline Average Personality & $\mathbf{6 7}$ & $\mathbf{3 7 . 2 2}$ & $\mathbf{3 0}$ & $\mathbf{3 3 . 3 3}$ & $\mathbf{3 7}$ & $\mathbf{4 1 . 1 1}$ \\
\hline Poor Personality & $\mathbf{2 7}$ & $\mathbf{1 5}$ & $\mathbf{2 2}$ & $\mathbf{2 4 . 4 4}$ & $\mathbf{0 5}$ & $\mathbf{5 . 5 6}$ \\
\hline & $\mathbf{1 8 0}$ & $\mathbf{1 0 0}$ & $\mathbf{9 0}$ & $\mathbf{1 0 0}$ & $\mathbf{9 0}$ & $\mathbf{1 0 0}$ \\
\hline
\end{tabular}

Statistical Analysis of Personality Adjustment Score of PGTs Working in Private School:

Calculated $\chi^{2}$ value is 12.5978 , which is greater than the $p$-value 0.001838 at $95 \%$ level of significance. So $\chi^{2}$ value is significant. Hence $3^{\text {rd }}$ null hypothesis can be rejected which means there is a significant difference in the personality adjustment of male and female PGTs working in private schools in Dehradun (Table 7).

Table 7:- Comparison of Scores of Male and Female PGTs Working in Private Schools.

\begin{tabular}{|l|l|l|l|l|ll|}
\hline \multirow{2}{*}{ PGTs } & \multicolumn{3}{|l|}{ Personality Adjustment } & \multirow{2}{*}{$\chi^{2}$-value } & Result & \\
\cline { 2 - 4 } & Good & Average & Poor & & Significant at & $\mathbf{9 5 \%}$ \\
\hline Male & $\mathbf{3 8}$ & $\mathbf{3 0}$ & $\mathbf{2 2}$ & $\mathbf{1 2 . 5 9 7 8}$ & level & \\
\hline Female & $\mathbf{4 8}$ & $\mathbf{3 7}$ & $\mathbf{0 5}$ &
\end{tabular}

Analysis of Scores of PGTs Working in Government Schools:

Table 8 indicates that out of 90 female PGTs, 41 PGTs have good personality adjustment, 34 female PGTs have average personality adjustment and 15 female PGTs have poor personality adjustment. Thus, $45.56 \%$ female teachers have good personality adjustment $37.78 \%$ female PGTs have average personality adjustment and $16.67 \%$ of female PGTs have poor personality adjustment. While out of 90 males PGTs, only 31 scored in good personality adjustment category and 31scored in poor personality category. Again it is clear that female PGTs have better personality adjustment as compared with male PGTs (Figure:1).

Table 8:- Score for Personality Adjustment of Government School PGTs.

\begin{tabular}{|l|l|l|l|l|l|l|}
\hline $\begin{array}{l}\text { Personality Adjustment } \\
\text { Category }\end{array}$ & Total PGTs & $\%$ & $\begin{array}{l}\text { Male } \\
\text { PGTs }\end{array}$ & $\%$ & $\begin{array}{c}\text { Female } \\
\text { PGTs }\end{array}$ & $\%$ \\
\hline Good Personality & $\mathbf{7 2}$ & $\mathbf{4 0}$ & $\mathbf{3 1}$ & $\mathbf{3 4 . 4 4}$ & $\mathbf{4 1}$ & $\mathbf{4 5 . 5 6}$ \\
\hline Average Personality & $\mathbf{6 2}$ & $\mathbf{3 4 . 4 4}$ & $\mathbf{2 8}$ & $\mathbf{3 1 . 1 1}$ & $\mathbf{3 4}$ & $\mathbf{3 7 . 7 8}$ \\
\hline Poor Personality & $\mathbf{4 6}$ & $\mathbf{2 5 . 5 6}$ & $\mathbf{3 1}$ & $\mathbf{3 4 . 4 4}$ & $\mathbf{1 5}$ & $\mathbf{1 6 . 6 7}$ \\
\hline Total & $\mathbf{1 8 0}$ & $\mathbf{1 0 0}$ & $\mathbf{9 0}$ & $\mathbf{1 0 0}$ & $\mathbf{9 0}$ & $\mathbf{1 0 0}$ \\
\hline
\end{tabular}

The one objective of this study was to compare personality adjustment of male and female PGTs working in government schools. The researcher calculated $\chi^{2}$ to find out significant difference between male and female PGTs with regard to their personality adjustment.

Table 9:- Statistical Analysis of Personality Adjustment of PGTs of Government Schools. 


\begin{tabular}{|l|l|l|l|l|l|}
\hline PGTs & Good & Average & Poor & & \\
\hline Male & 31 & 28 & 31 & \multirow{2}{*}{7.5348} & $\begin{array}{c}\text { Significant at 95\% } \\
\text { (P value .023113) }\end{array}$ \\
\cline { 1 - 4 } Female & 41 & 34 & 15 & & \\
\hline
\end{tabular}

Calculated $\chi^{2}$ value is 7.5348 at $95 \%$ level of significance which is greater than the p-value 0.117809 . Hence $4^{\text {th }}$ null hypothesis is rejected. It is concluded that there is a significant difference in the personality adjustment of male and female PGTs working in government schools (Table 9).

\section{Analysis of Scores Obtained for Male PGTs:}

The researcher tried to describe personality adjustment of males working in private and government school separately. Table: 10 presents number and percentage of private and government school male PGTs belonging to different personality adjustment categories.

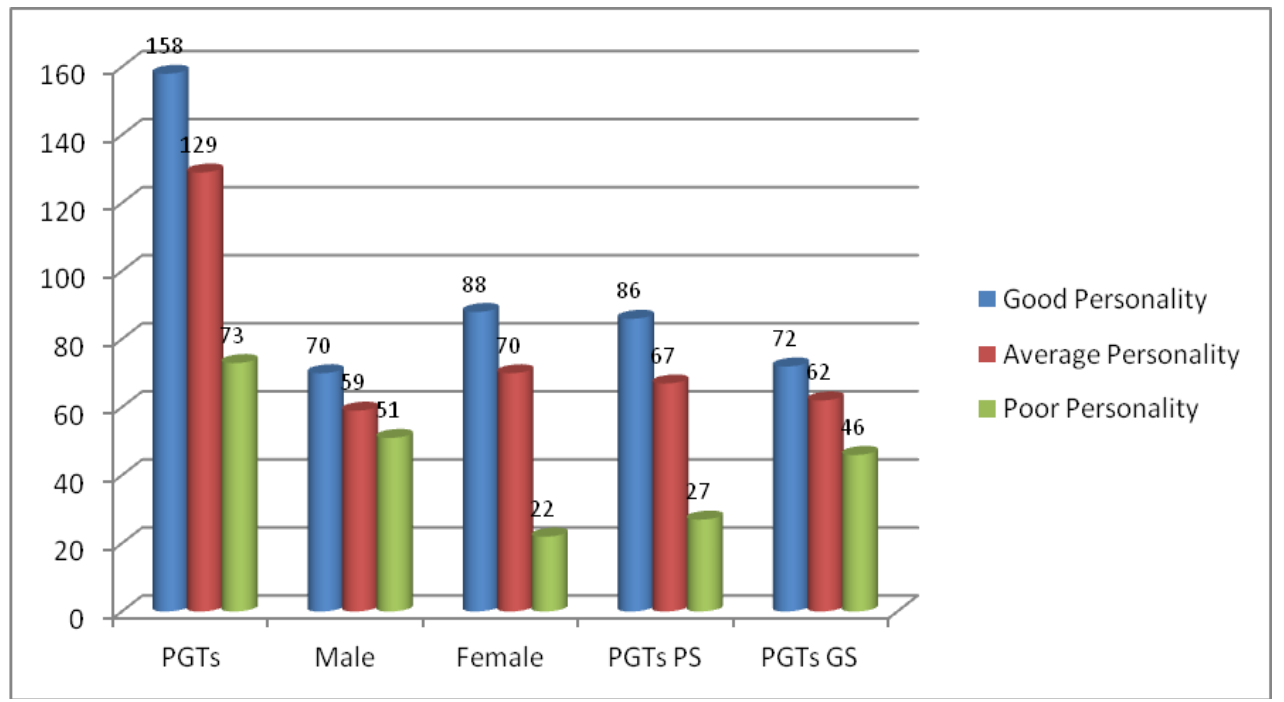

Figure 1:- Scores for Personality Adjustment of Male and Female PGTs.

\section{PS: Private schools; GS: Government schools}

It is clear from table 10, that among male PGTs, $42.22 \%$ private school male PGTs have good personality adjustment as compared with $34.44 \%$ working in government schools. $33.33 \%$ males from private school scored for average personality adjustment as compared with $31.11 \%$ male from government schools. While $34.44 \%$ males of government schools scored in poor category of personality adjustment as compared with $24.44 \%$ male PGTs of private schools. Overall $75.55 \%$ male PGTs of private schools are above poor level of personality adjustment while only $65.55 \%$ male PGTs of government school are above poor level of personality adjustment. It is clear that male PGTs working in private schools have much better personality adjustment as compared with those working in government schools.

Table 10:- Comparison of Personality Adjustment of Male PGTs.

\begin{tabular}{|l|l|l|l|l|l|}
\hline Adjustment Category & Total PGTs & Male PGTs & \multicolumn{3}{l|}{} \\
\cline { 3 - 6 } & & Pvt. & $\%$ & Govt. & $\%$ \\
\hline Good personality & $\mathbf{7 0}$ & $\mathbf{3 8}$ & $\mathbf{4 2 . 2 2}$ & $\mathbf{3 1}$ & $\mathbf{3 4 . 4 4}$ \\
\hline Average personality & $\mathbf{5 9}$ & $\mathbf{3 0}$ & $\mathbf{3 3 . 3 3}$ & $\mathbf{2 8}$ & $\mathbf{3 1 . 1 1}$ \\
\hline Poor personality & $\mathbf{5 1}$ & $\mathbf{2 2}$ & $\mathbf{2 4 . 4 4}$ & $\mathbf{3 1}$ & $\mathbf{3 4 . 4 4}$ \\
\hline Total & $\mathbf{1 8 0}$ & $\mathbf{9 0}$ & $\mathbf{1 0 0}$ & $\mathbf{9 0}$ & $\mathbf{1 0 0}$ \\
\hline
\end{tabular}

Calculated $\chi^{2}$ value is 2.3074 at $95 \%$ level of significance. While $\mathrm{p}$ value is 0.315465 . Which means it is not a significant value so we can accept null hypothesis $5^{\text {th }}$. Hence it is concluded that there is no significant difference in the personality adjustment of male PGTs working in private and government schools (Table 11). 
Table 11:- Comparison of Personality Adjustment of Male PGTs Working in Private and Government School.

\begin{tabular}{|l|l|l|l|l|l|}
\hline \multirow{2}{*}{ Male PGTs } & \multicolumn{2}{|l|}{ Per Personality Adjustment } & \multirow{2}{*}{$\chi^{2}$ Value } & Result \\
\cline { 2 - 5 } & Good & Average & Poor & & \\
\hline Private & $\mathbf{3 8}$ & $\mathbf{3 0}$ & $\mathbf{2 2}$ & $\mathbf{2 . 3 0 7 4}$ & $\begin{array}{l}\text { Not Significant 95\% } \\
\text { (P value .117809) }\end{array}$ \\
\hline Government & $\mathbf{3 1}$ & $\mathbf{2 8}$ & $\mathbf{3 1}$ & & \\
\hline
\end{tabular}

Analysis of Scores Obtained for Female PGTs:

Table 12 present numbers and percentage female PGTs working in private and government school belonging to different personality adjustment categories. 53.33\% female PGTs of private school scored under good personality adjustment as compared with $45.56 \%$ of government school female PGTs. While $41.11 \%$ female PGTs of private schools are in the category of average personality adjustment as compared with female PGTs working in government schools in Dehradun as compared with $37.78 \%$ female PGTs of government schools. It's clear that female PGTs working in private schools have better personality adjustment.

Table 12:- Comparison of Personality Adjustment of Female PGTs.

\begin{tabular}{|l|l|l|l|l|l|}
\hline \multirow{2}{*}{ Adjustment Category } & Total PGTs & Female PGTs & \multicolumn{2}{l|}{} \\
\cline { 3 - 6 } & & Pvt. & \% & Govt. & $\%$ \\
\hline Good personality & $\mathbf{8 8}$ & $\mathbf{4 8}$ & $\mathbf{5 3 . 3 3}$ & $\mathbf{4 1}$ & $\mathbf{4 5 . 5 6}$ \\
\hline Average personality & $\mathbf{7 0}$ & $\mathbf{3 7}$ & $\mathbf{4 1 . 1 1}$ & $\mathbf{3 4}$ & $\mathbf{3 7 . 7 8}$ \\
\hline Poor personality & $\mathbf{2 2}$ & $\mathbf{0 5}$ & $\mathbf{5 . 5 6}$ & $\mathbf{1 5}$ & $\mathbf{1 6 . 6 7}$ \\
\hline Total & $\mathbf{1 8 0}$ & $\mathbf{9 0}$ & $\mathbf{1 0 0}$ & $\mathbf{9 0}$ & $\mathbf{1 0 0}$ \\
\hline
\end{tabular}

Table 13:- Comparison of Personality Adjustment of Female PGTs.

\begin{tabular}{|l|l|l|l|l|l|}
\hline \multirow{2}{*}{ Female PGTs } & \multicolumn{2}{|l|}{ Per Personality Adjustment } & \multirow{2}{*}{$\chi^{2}$ Value } & \multirow{2}{*}{ Result } \\
\cline { 2 - 4 } & Good & Average & Poor & & \\
\hline Private School & $\mathbf{4 8}$ & $\mathbf{3 7}$ & $\mathbf{5}$ & $\mathbf{5 . 6 7 7 3}$ & $\begin{array}{l}\text { Not Significant 95\% } \\
\text { (P value .058504) }\end{array}$ \\
\hline Government School & $\mathbf{4 1}$ & $\mathbf{3 4}$ & $\mathbf{1 5}$ & & \\
\hline
\end{tabular}

Calculated $\chi^{2}$ value is 5.6773 at $95 \%$ level of significance. While $\mathrm{p}$ value is 0.058504 . Which means it is not a significant value so we can accept null hypothesis $6^{\text {th }}$. Hence it is concluded that there is no significant difference in the personality adjustment of male PGTs working in private and government schools (Table 13).

\section{Major Findings of The Study:}

The following findings were drawn on the basis of analysis and interpretation of the data:

1. PGTs working in private schools have much better personality adjustment as compared with government school PGTs.

2. More female PGTs have good personality adjustment as compared with male PGTs and difference is very high.

3. It was observed that more females working in private and government schools in Dehradun have good personality adjustment as compared with male PGTs working in same schools.

4. Among male PGTs, those working in private schools, have better personality adjustment as compared to those working in government schools.

5. Female PGTs working in private schools have much better personality adjustment as compared with working in government schools in Dehradun.

\section{Discussion and Conclusion:-}

Male PGTs have poor personality adjustment as compared with female PGTs. Reason as discussed with PGTs is that male PGTs are less recognized and acknowledged. Similarly, there is a significant difference in the personality adjustment relating to gender and types of schools. PGTs working in private schools in Dehradun have much better personality adjustment as compared with PGTs working in government schools. Same time female PGTs have better personality adjustment as compared with male PGTs working private and government schools in Dehradun.

From this study it is concluded that there is a greater difference in the personality adjustment. Hence, in order to achieve all the objectives of education, teachers should have good personality adjustment. To improve these conditions, management should take proper steps for goodwill of teaching staff. 
Teachers should be well adjusted in their profession to give the best possible to students for the development of a nation. Teachers working in private schools have better personality adjustment. All the teachers had not enjoyed the higher level of personality adjustment. Therefore, necessary facilities should be made available for increasing qualities of teachers and creating an effective teaching-learning environment in every institution.

\section{Delimitations and Suggestions:-}

There is no meaningful research that does not provide cause for further investigation. In fact by universal opinion and experience, the solution of one problem tends to indicate many other unsolved problems, waiting for scientific probing. So, in the whole process of this piece of research the investigator however, feels to pen-down the following suggestions for the future researchers.

1. The study as confined only to Dehradun, it is therefore suggested that study may be conducted in other cities to increase comprehensiveness of its conclusions.

2. The sample of only 360 PGTs was selected for this study. A study may be conducted on large sample to search very definite conclusions regarding job anxiety, Job satisfaction and personality adjustment.

3. Such a study can be conducted for the sample of TGTs and college level also.

4. Personality adjustment of the PGTs of various disciplines like natural sciences and social sciences can be measured.

5. Different variables like work load, work habits, age, experience, interests, adjustment and self-concept can be undertaken in relation to Job anxiety and satisfaction

6. A study should be conducted to find out the remedial measures for the stress of teachers.

7. Qualitative analysis could have proved more useful.

\section{Acknowledgement:-}

The author would like to express sincere thanks to Dr.Sangeeta Khullar Associate Professor MKPG College, and incharge Psychology Department IGNOU study centre Dehradun for her continuous motivation and appreciation. I would like to thank from the core of my heart to Mr.H.S.Mann (Director), Ms. Sonika Mann (Finance Director), Dr.Gurbir Dullet (Rehabilitation psychologist and counselor), and Ms. Sanjoo singh (senior school coordinator), Doon International School, Dehradun, Uttarakhand, India.

The research was not funded by any agency and it was performed in 2019 .

\section{Conflict of interest:}

Author has declared that no competing interest exists.

\section{References:-}

1. Agarwal, V. (1983), "A Study of Stress Processes, Adjustment and Job-satisfaction as Predictors of Administrative Effectiveness of Principals", in 4th Survey of Research in Education by M.B. Buch (1983-88), N.C.E.R.T.

2. Anju Goyat, "A Study Of Adjustment Level Among Primary School Teachers In Jhajjar”, IJTBM, 2012, Vol. No. 1, Issue No. 6, Apr-Jun.

3. Arora, R.K. (1992), "International Effect of Creative and Intelligence on Emotional Stability, Personality Adjustment and Academic Achievement", Indian Educational Review, Vol. 26, No. 3. 3. Alton-Lee, A. \& Praat, A. (2000).

4. Bharat Kumar 2020, Study of Job Anxiety among Post Graduate Teachers in Dehradun, International Journal of Science and Research (IJSR), 9(3), DOI: 10.21275/SR20314201126

5. B. Kumar (2019). Examination Stress among Adolescents of Dehradun: Impact of Personality, Intelligence and Achievement Motivation. International Journal of Indian Psychology, 7(1), 158-176. DIP:18.01.018/20190701, DOI:10.25215/0701.018.

6. Banga, U.S. (1983), "Impact of Teacher Training Programme in Physical Education on the Physical Fitness Personality, Adjustment and Motivity", in 3rd Survey of Research in Education by M.B. Buch (1983-88), Baroda.

7. Chadha, D.K. (1985), "Self-Concept of Teachers and their Emotional Adjustment", in 4th Survey of Research in Education by M.B. Buch (1983-88)s, N.C.E.R.T. 
8. Malik, K.K. (1996), “A Comparative Study of the Achievement of B.Ed. Male and Female Pupil - Teachers in Relation to Their Adjustment and Reading Interests", M. Phil. Dissertation, Department of Education, M.D.U. Rohtak.

9. Mangal, S.K. (1979), “Analysis of Common Factors in Teacher Adjustment”, Ph. D. Thesis, Department of Education, K.U. Kurukshetra.

10. "Measuring Adjustment of Teacher" (1984), Journal of Education and Psychology, Vol. 42, No. 3.

11. Manpreet, (2002), "A Study of Burn-out and Adjustment Pattern of Primary School Teachers in Haryana", M.Ed. Dissertation, Department of Education, K.U. Kurukshetra. 